\title{
ЭФФЕКТИВНАЯ МОДЕЛЬ ВТОРИЧНОГО ИСПОЛЬЗОВАНИЯ СТРОИТЕЛЬНЫХ ОТХОДОВ В ПРОЦЕССЕ ДЕКОНСТРУКЦИИ ПРОМЫШЛЕННЫХ ОБЬЕКТОВ
}

\author{
Бейзым Д.М. ${ }^{1}$ \\ Кондратьева Т.Н. ${ }^{2}$ \\ Норвежский государственный университет, Будё, Норвегия \\ МГИМО (университет) МИД РФ, г. Москва, Россия \\ ${ }^{2}$ Донской государственный технический университет, \\ г. Ростов-на-Дону, Россия
}

В данной статье были использованы принципь циркулярной экономики и замкнутых ииклов, предложен эффективныи подход $к$ вторичному использованию строительных отходов в прочессе деконструкиии промышленных объектов.

Ключевые слова: циркулярная экономика, экономика природопользования, энергия, энергопотребление, углекислый газ, окружающая среда.

Переработка и повторное использование бетона. По данным ВВС, журнала «Наука и окружающая среда» [1], бетон считается вторым наиболее широко используемым ресурсом в мире после воды. Несмотря на то, что древние римляне всегда были известны своим умелым использованием упомянутого строительного материала задолго до его массового производства, согласно BBC Journal 2018, производство бетона отвечает за около 8\% мировых выбросов $\mathrm{CO}_{2}$. Учитывая современные тенденции глобального потепления, повторное использование существующих бетонов может быть благоприятной возможностью, ведущей к более устойчивому миру. Результатом умственной деятельности как раз и являются информационные продукты, которые объединяют в себя совокупность определенных данных и формируются самим производителем и которые отражают его взгляд и представление о том, в какой предметной области создается сам продукт.

Повторное использование бетона обеспечивает ряд преимуществ, таких как:

- снижение затрат на поставку материалов;

- снижение выбросов $\mathrm{CO}_{2}$ в атмосферу;

- свободное пространство от хранилища бетона;

- ненужная добыча гравия с дальнейшей его транспортировкой;

- потенциальная государственная поддержка политики снижения сборов за строительство (в зависимости от страны);

- перенаправление рабочей силы с добычи необходимого гравия на более безопасную отрасль переработки. 
Стоит упомянуть, что утилизация бетона также включает в себя тяжелую технику, такую как портативные дробилки, которые обычно работают на дизеле. Но есть и более экологически чистые версии, такие как электродизельные гибриды, которые, как следствие, уменьшают количество вредных выбросов в атмосферу и экономят до $30 \%$ топлива, влияя на более низкие эксплуатационные расходы [2].

Другим важным аспектом, на который следует обратить внимание, является процесс отделения, при котором используются сильные магниты для отделения бетонных деталей от металла, которые могут в дальнейшем использоваться в строительной деятельности. После вторичной ударной процедуры другие побочные продукты отделяются с помощью процедуры просеивания, где грязь и другие частицы отделяются от бетона вместе с более крупным заполнителем [3].

Дальнейшее использование полученного вещества:

- агрегат для смешивания нового бетона;

- проницаемое покрытие для пешеходных дорожек, проезжей части и других наружных твердых поверхностей;

- ландшафтная мульча: при правильном измельчении и хорошей сортировке, земляной бетон может заменить речной камень или другой гравий, используемый в качестве грунтового покрытия и мульчи;

- материал для строительства новых местообитаний океанических рифов.

В целом, процессы переработки бетона имеют больше преимуществ, влияющих на устойчивый подход к снижению количества производимого бетона. Несмотря на то, что невозможно полностью избавиться от производства цемента, потому что это доступный и надежный строительный материал, в котором переработанный бетон может использоваться лишь частично в новой системе.

Обработка и повторное использование металлов [4]. Для того, чтобы собрать металл из разрушенной конструкции - может быть использовано автоматическое или управляемое вручную оборудование. Но, несмотря на механические процедуры, применяемые для извлечения металла из куска бетона, жизненно важно отделить черные и цветные металлы, которые можно выполнить с помощью магнита. Наиболее распространенные металлы, которые можно найти в процессе сноса: алюминий, железо, нержавеющая сталь, сталь, медь и латунь. Если для разделения различных черных и цветных металлов не используется человеческий труд, то для разделения материалов используются датчики автоматизированных операций по переработке [5]. После того, как металлы отсортированы в соответствии с их свойствами, они измельчаются и собираются для дальнейшего плавления. Тем не менее, важно отметить, что процесс переработки и плавления использованных металлов требует гораздо меньше энергии, чем те же процессы, в которых используется сырье. Более того, согласно докладу об экологических выгодах утилизации Бюро 
международной переработки (BIR) - при переработке металлов образуется значительно меньшее количество $\mathrm{CO}_{2}$ в атмосферу [6].

Преимущества переработки металлов:

- металлолом всегда пользуется высоким спросом и легко возвращается на рынок;

- снижение энергопотребления процессов переработки по сравнению с переработкой сырья;

- перенаправление рабочей силы с добычи необходимых металлов в более безопасную область индустрии переработки;

- снижение выбросов $\mathrm{CO}_{2}$ в атмосферу;

- свободное земельное пространство от склада металлолома.

Дальнейшее использование полученных веществ:

Как уже упоминалось ранее, рынок металлолома очень развит, и для продолжения устойчивой цепочки циклической экономики можно использовать следующие торговые ассоциации по переработке металлов: ISRI (Институт переработки металлолома Inc), BMRA (Британская ассоциация по переработке металлов), AMRIA: AMRIA (Австралийская ассоциация промышленности по переработке металлов) - которая уже может направлять конечный переработанный продукт на строительство, в ИТ, гражданское электроснабжение и другие предприятия.

Обработка и повторное использование стекла / окон. Другим материалом, который присутствует практически в любом здании, которое не считается бункером, является плоское стекло или окна. Совершенные технологии для изготовления новых окон из старых еще не появились, но уже в 2012 году была представлена концептуальная теоретическая идея модели переработки любых стеклянных материалов [7].

Стоит отметить, что стекло является одним из самых сложных веществ для переработки, и если говорить об обычных стеклянных изделиях, таких как чашки и бутылки, процесс переработки включает плавление его в печи. Кроме того, различные стекла включают в себя различные химические вещества, что делает процесс переработки намного сложнее [8].

Это делается для того, чтобы сделать структуру стекла более прочной, но в то же время значительно усложняет преобразование материала в единый однородный компонент. Одной из возможностей утилизации плоского стекла или окон в условиях начала XXI века является их повторное использование путем пожертвования Habitat для Humanity ReStore, который является независимым магазином повторного использования, расположенным в Европе, на Ближнем Востоке, в Африке и Северной Америке. В случае, если это невозможно, новые возможности, связанные с инновационным восстановлением, могут быть применены посредством обновления старых окон до так называемых SolarWindows, которые с применением технологии напыления позволяют превратить обычное окно в экран, генерирующий солнечную энергию [9]. 
В заключение следует отметить, что, согласно данным Международного энергетического агентства, промышленность по производству контейнеров и листового стекла (на которую приходится $80 \%$ производства стекла) выделяет более 60 мегатонн $\mathrm{CO}_{2}$ в год (IEA 2007), следовательно, переработка этого материала будет полезным для окружающей среды и уровня углекислого газа в атмосфере [10].

Преимущества переработки стекла:

- возможность внести свой вклад в сектор возобновляемой энергии, превратив старые окна в солнечные электростанции;

- снижение выбросов $\mathrm{CO}_{2}$ в атмосферу;

- свободное пространство от склада стекла;

- переработка и повторное использование кирпича.

Другим компонентом, который нужно позаботиться после сноса промышленного объекта, является кирпичный материал. Если материал не поврежден, его можно использовать повторно напрямую. Если кирпичи повреждены, всегда можно придать им форму или обрезать, пока они не достигнут желаемой формы [11].

Но в основе идеи дальнейшего использования кирпичных конструкций лежит тот факт, что он сделан из ценных в строительной промышленности глин, сланцев и других полезных ископаемых, включая гравий, который непосредственно используется при производстве бетона. Следовательно, в сочетании с переработанным бетоном можно добиться возможности использования переработанного кирпича в качестве бетонного заполнителя, снижая дальнейшие выбросы $\mathrm{CO}_{2}$ и потребление сырья в целом.

Чтобы закончить с кирпичами, стоит упомянуть, что, согласно www.claybrick.org, средний объем производства 1 кг глиняного кирпича в Южной Африке дает 0,27 кг выбросов в эквиваленте $\mathrm{CO}_{2}$, что равно 2,6 млн. Тонн выбросов в эквиваленте $\mathrm{CO}_{2}$ в год [12]. Следовательно, минимизирую производство кирпича, человечество может достичь более низких показателей выработки $\mathrm{CO}_{2}$.

Преимущества переработки кирпича:

- синергия полезного минерального компонента кирпичной структуры и переработанного бетона для производства новых устойчивых бетонных конструкций без добычи нового гравия;

- снижение выбросов $\mathrm{CO}_{2}$ в атмосферу;

- перенаправление рабочей силы с добычи необходимого гравия на более безопасную отрасль переработки;

- свободное земельное пространство от хранения кирпича.

Выводы.

Устойчивая модель разрушения промышленного объекта предполагает учет всех материалов и ресурсов, которые уже находятся в системе, а также их дальнейшую переработку и повторное использование. Чтобы поддерживать уровень эффективности в соответствии с устойчивой моделью, очень важно четко понимать, что потенциально может быть сделано с каждым отдельным 
компонентом системы. Более того, несмотря на стремление использовать материалы, задействованные в системе, на 100\%, усилия должны быть направлены на экономическую эффективность, когда стоимость обработки и сборки не должна превышать первоначальные производственные затраты. Но чтобы понять общую эффективность каждого действия при сносе промышленного объекта, крайне важно изучить каждый отдельный компонент в отдельности, например: металл, включая глинозем, сталь, медные провода; деревянные конструкции; бетонные конструкции, кирпичи, трубопроводные системы, стекло / окна и т. д.

\section{Список литературы}

1. Электронный pecypc: https://www.bbc.com/news/science-environment46455844.

2. Электронный ресурс: https://www.rubblemaster.com/us/products/ mobilecrushing/.

3. Электронный pecypc: https://www.thebalancesmb.com/recyclingconcrete-how-and-where-to-reuse-old-concrete-844944

4. Электронный pecypc: https://sheetpiling.arcelormittal.com/en/susta inability/circular-economy-recycle/

5. Электронный pecypc: https://www.thebalancesmb.com/an-introductionto-metal-recycling-4057469

6. Электронный pecypc: https://www.mgg-recycling.com/wpcontent/uploads/2013/06/BIR_CO_2_report.pdf

7. Электронный pecypc: https://agc-flattoflat.eu/wpcontent/uploads/2017/01/Recycling-of-Glass-from.pdf

8. Электронный pecypc: https://earth911.com/home/house/recyclingmystery-windows/

9. Электронный pecypc: https://www.solarwindow.com/

10. Электронный pecypc: https://china.lbl.gov/sites/default/files/lbl_glass _final.pdf

11. Ajukumar V., Gandhi O. Evaluation of green maintenance initiatives in design and development of mechanical systems using an integrated approach. Journal of Cleaner Production, 2013, vol. 51, pp. 34-46.

12. Электронный pecypc: https://www.hablakilns.com/cutting-co2-emissionsin-brick-making/ 